\title{
A Revised Formula to Compute Shear Strength of Unsaturated Soils
}

\author{
Huajin $\mathrm{Li}^{1}$, Wenkai Feng ${ }^{1 *}$, Qiang $\mathrm{Xu}^{1}$, Yusen $\mathrm{He}^{2}$, Boyu $\mathrm{Luo}^{1}$, Shiyang Chen ${ }^{3}$ \\ ${ }^{1}$ State Key Laboratory of Geohazard Prevention and Geoenvironment Protection, Chengdu University of Technology, 1 \\ Erxianqiao East Rd., Chengdu, Sichuan, China, 610059 \\ ${ }^{2}$ Intelligent Systems Laboratory, Seamans Center, Mechanical and Industrial Engineering, the University of Iowa, Iowa City. \\ Iowa, U.S. 52242 \\ ${ }^{3}$ The University of Iowa, Iowa City, Iowa, U.S. 52242
}

\begin{abstract}
In the western part of Sichuan province of China, moraines are widely distributed along the Valley of Zagunao River. The moraines at high altitude have deformed constantly under the influence of precipitation. It is considered as a severe threat to the local community. By on-site geological investigation and lab experiments, the sensitivities of moraines under different saturation rates are observed. The cohesion and friction angle both have negative correlations with the saturation rates of the morainic materials. Traditional mechanical strength models for unsaturated soil analysis failed to explain the mechanical characteristics explicitly. A revised Mohr-Coulomb criterion formula with an added cohesive compensation is proposed in this research to compute the unsaturated strength. The revised criterion accurately predicts the strength and is valuable for future research of special types of breccia.
\end{abstract}

Keywords: moraines, sensitivity analysis, mechanical strength mode, SWCC, cohesive compensation

\section{Introduction}

In the western part of Sichuan province, moraines are widely distributed along the Zagunao river. At some locations, large accumulations of moraines formed, and finally developed into big slopes. These slopes have been experiencing a significant deformation process for a long time and they are still unstable. There are villages and small towns along the river valley, the instability of these slopes is a great threat to the local residents. Our long-term observation showed that the stability is decreased by precipitation or earthquakes. Under precipitation, the mechanical strength of these accumulations drops sharply. Under intense precipitation, the morainic forms will change. Hence, the research on the evolution of its stability and especially the correlation between mechanical strength and Moisture content is vital. The large slope in Xiaoqi village in Western Sichuan was analyzed as a case study in our research (Fig. 1).

Before 2006, the structure of the accumulation was relatively stable in Xiaoqi village and collapses rarely occurred in the front side. However, in 2007, the China National Railway Company started the construction on the front platform (Fig. 1b). This activity caused the deformation of the accumulation slopes. Our records in on-site geological investigation indicated the movements at the speed of maximum $2 \mathrm{~cm}$ per day. In 2008, the deformation increased because of the Wenchuan earthquake. Several collapses were observed in the front area. In recent years, the deformation still occurs at a lower speed. These observations suggest that the precipitation and earthquake accelerate the deformation. Therefore, threat to the local communities as well as the highway \#317 is obvious. This necessitates research on the moving mechanisms. Most of the moraines are located at high altitude. As the built-up areas began to expand to high altitude, researches on the effects of construction on the stability of these moraines have become urgent in recent years. In previous investigations, the internal geological structure of the moraines, the formation of these accumulations and their mineral composition have been analyzed (Gens and Alonso 1992, Xu 2000, Zeng 2014). However, there exists but little information about the hydrological conditions of these moraines. It is necessary to conduct research on the correlation between mechanical strength and the Moisture content.

\section{Literature Review}

In the last century, there was a rapid development of the theories about the mechanical characteristics of saturated soil. Some of them have been well developed and applied in the field of rock and soil mechanics (Barden et al 1973, Whitman 1984, Gong 2000, Soonkie et al 2011) Unsaturated soil functions as a membrane due to the existence of gas-phase. Their physical properties are different from saturated soil (Fredlund and Rhadajo 1993). Hence, the classical soil mechanics based on the study of mechanical properties of

* Corresponding Author: Wenkai Feng, email: fwkhyl@,163.com 
saturated soil cannot be applied to unsaturated soil.

The mechanical strength of the unsaturated soil increases with an increase in the matric suction. Both matric suction and shear strength are affected by the change of saturation which corresponds to the change of soil volume (Sheng and Yang 2012). Accordingly, research on the mechanical properties of unsaturated soil cannot be accomplished without the mathematical description of the soil-water characteristic curve (SWCC). The mathematical expression of the SWCC for unsaturated soil is critical for the development of strength formula and its constitutive relation. Currently, there are totally four types of mathematical models designed for the SWCC (Sheng 2011). They are listed as follows: Log-exponential model proposed by Fredlund et al (Fredlund and Morgenstern 1977, Fredlund and Rhadajo 1993), Exponential model proposed by van Genuchten and Leiji (1992), Multi-fractal model proposed by Campbell (1974), and Non-linear logarithmic model proposed by Brooks and Corey (1964).

In most cases, researchers still use the Mohr-Coulomb
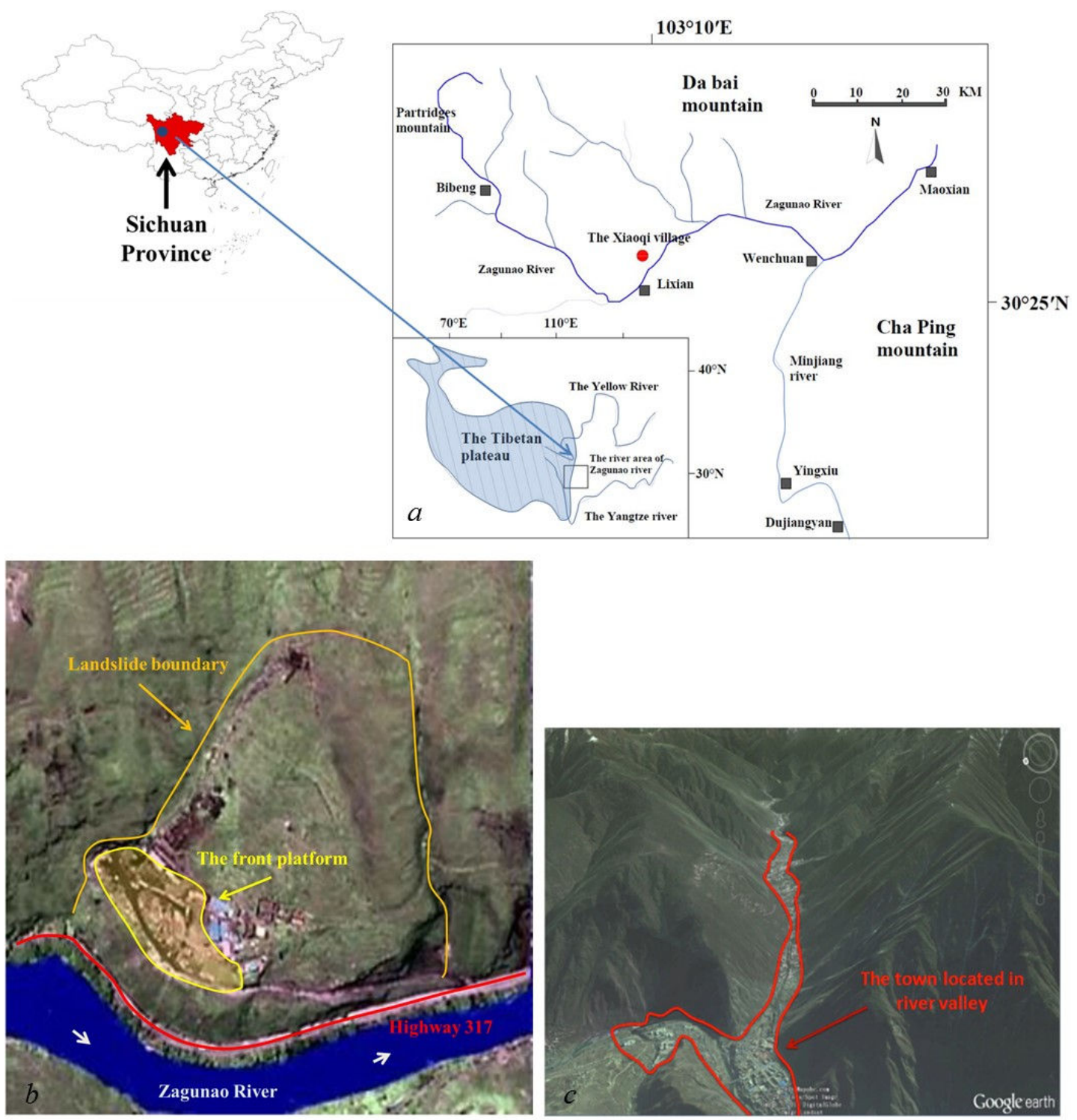

Fig. 1 The study area. a) studied valley location; b) the accumulation of moraines in the river valley (from Google earth); c) the town located in river valley.

criterion to construct formulas to express the mechanical strength of unsaturated soil. However, those formulas cannot be simply deduced from the theory of saturated soil mechanics. The research on unsaturated strength has been conducted by Croney et al (1958), Biship (1959), Coleman (1962), Jennings and Burland (1962), Bishop and Blight (1963), Blight (1967), Fredlund and Morgenstern (1977),
Fredlund and Rhadajo (1993), Zheng et al (1994), Yang et al (2004), Xu (2005), Çokça and Tilgen (2010). The results indicate that the deformation of soil is affected by negative pore pressure and different formulas of effective stress have been proposed.

Bishop (1959) proposed a shear strength measurement method based on the principle of effective stress. After he 
proposed the effective stress theory for unsaturated soil, Jennings and Burland (1962) argued that collapse on wetting phenomenon of unsaturated soil cannot be explained based on Bishop's theory. To verify that, they conducted collapse tests on three different soils: silt, silty sand, and silty clay. The collapse on wetting phenomenon was observed in all samples. Nevertheless, their results proved that Bishop's effective stress formula failed to predict the values under a certain degree of saturation. Meanwhile, they also found that there is no global correlation between saturation rate and effective stress.

To overcome the deficiencies mentioned above, Coleman (1962) , Bishop and Blight (1963), and Blight (1967) proposed to use two independent stress variables, namely effective stress and matric suction, to express the deformation process of the unsaturated soil. Null tests were proposed by Fredlund and Morgenstern (1977), and Fredlund and Rhadajo (1993). They employed the two independent variables (e.g., effective stress and matric suction) at the same time to describe the mechanical strength and deformation characteristics of the unsaturated soil. In recent years, based on Bishop's method, many researchers have achieved some progress to express the characteristics of unsaturated soil using effective stress and suction as two independent variables. By using models with two independent stress variables, the soil-water characteristic curves (SWCCs) can be fitted well.

Presently, the most famous ones are the formula of effective stress proposed by Bishop (1959) and the formula with two state stress variables (effective stress $\left(\sigma-\mu_{a}\right)$ and matric suction $\left.\left(\mu_{a}-\mu_{w}\right)\right)$ proposed by Fredlund and Rhadajo (1993) (Table 1).

However, the mechanics of unsaturated soil is still not well-developed because of the technical limitations in laboratory experiments. Consequently, the practical application of unsaturated soil mechanics in engineering geology and geotechnical engineering is rare.

Table 1 Shear strength formulas proposed by Bishop and Fredlund

Shear strength models

\begin{tabular}{lll}
\hline Bishop & $\tau_{f}=c^{\prime}+\left(\sigma-\mu_{a}\right) \tan \varphi^{\prime}+X\left(\mu_{a}-\mu_{w}\right) \tan \varphi^{\prime}$ & $X$ is a parameter of effective stress; $0 \leq X \leq 1$ \\
\hline Fredlund & $\tau_{f}=c^{\prime}+\left(\sigma-\mu_{a}\right) \tan \varphi^{\prime}+\left(\mu_{a}-\mu_{w}\right) \tan \varphi^{b}$ & $\begin{array}{l}\varphi^{b} \text { is a variable that describes the rate of change in shear } \\
\text { strength relative to changes in matric suction. }\end{array}$
\end{tabular}

${ }^{*} \tau_{f}$ is the shear stress on the failure plane at failure; $c^{\prime}$ and $\varphi^{\prime}$ are the effective shear strength parameters; $\left(\sigma-\mu_{\alpha}\right)$ is the net normal stress at failure; $\left(\mu_{a}-\mu_{w}\right)$ is the matric suction; $\sigma$ is the total normal stress at failure; $\mu_{a}$ is the pore-air pressure; $\mu_{w}$ is the porewater pressure.

Table 2 Mechanical parameters of moraines

\begin{tabular}{|c|c|c|c|c|c|c|c|c|c|}
\hline \multirow{2}{*}{$\begin{array}{l}\text { Particle } \\
\text { specific } \\
\text { gravity }\end{array}$} & \multirow{2}{*}{$\begin{array}{l}\text { Natural } \\
\text { weight } \\
\left(\mathrm{g} / \mathrm{cm}^{3}\right)\end{array}$} & \multirow{2}{*}{$\begin{array}{c}\text { Saturated } \\
\text { weight } \\
\left(\mathrm{g} / \mathrm{cm}^{3}\right)\end{array}$} & \multirow{2}{*}{$\begin{array}{c}\text { Moisture } \\
\text { content } \\
(\%)\end{array}$} & \multirow{2}{*}{ Void } & \multirow{2}{*}{$\begin{array}{l}\text { Saturation } \\
\text { rate }\end{array}$} & \multicolumn{4}{|c|}{ Breccia size distribution / \% } \\
\hline & & & & & & $\begin{array}{c}>2.00 \\
\mathrm{~mm}\end{array}$ & $\begin{array}{c}2.00-0.15 \\
\mathrm{~mm}\end{array}$ & $\begin{array}{c}0.15-0.076 \\
\mathrm{~mm} \\
\end{array}$ & $\begin{array}{c}<0.076 \\
\mathrm{~mm}\end{array}$ \\
\hline 2.824 & 19.42 & 20.45 & 5.25 & 0.75 & 27.96 & 51.90 & 29.75 & 18.52 & 2.53 \\
\hline
\end{tabular}

\section{Experiment Design and Results}

Previous research has already indicated the significant correlation between the mechanical strength and the moisture content (Wheeler et al 2003, Sheng et al 2004). Because of dry weather in the study area, research on the relationship between degree of saturation and shear strength is important.

\subsection{Soil-Water Characteristic Curve}

Based on the above analysis, we know that the moraine has a very strong sensitivity to water. So drying test and wetting test were applied, and Geo-Experts (3D-SDSWCC) was used to derive the relationship between Matric suction $\left(\mu_{a}-\mu_{w}\right)$ and volumetric moisture content (degree of saturation).

The samples used in the laboratory experiments were taken from the sliding zone above Xiaoqi Village and their physical properties are listed in Table 2. Geo-Experts (3DSDSWCC) was utilized to perform the measurements for the SWCC with a repetition of the wetting-drying path. In most cases, a negative correlation between the moisture content and the matrix suction exists. The consolidation tests by previous researchers indicate that at suction values beyond the point of air entry, soils samples enter an elastic region marked by a drastic reduction in the volume change with suction. There is a certain level of elastic dilatancy. At suction values below the air entry, a greater level of elastic dilatancy than in the unsaturated region is observed (Khalili et al 2004).

To analyze the values of matric suction under different saturation levels, the drying and wetting processes of the unsaturated soil were implemented using volume-pressure 
plate extractor to obtain the SWCC of morainic soil.

The experimental procedures are as follows: firstly, the soil sample was saturated to $100 \%$. Secondly, the air was extracted under the plate and the water was filled in. Then the sample was connected to the burette which was used to record water volumetric changes by observing the ruler on it. Finally, the saturated samples were put on the plate, as shown in Fig. 2a.
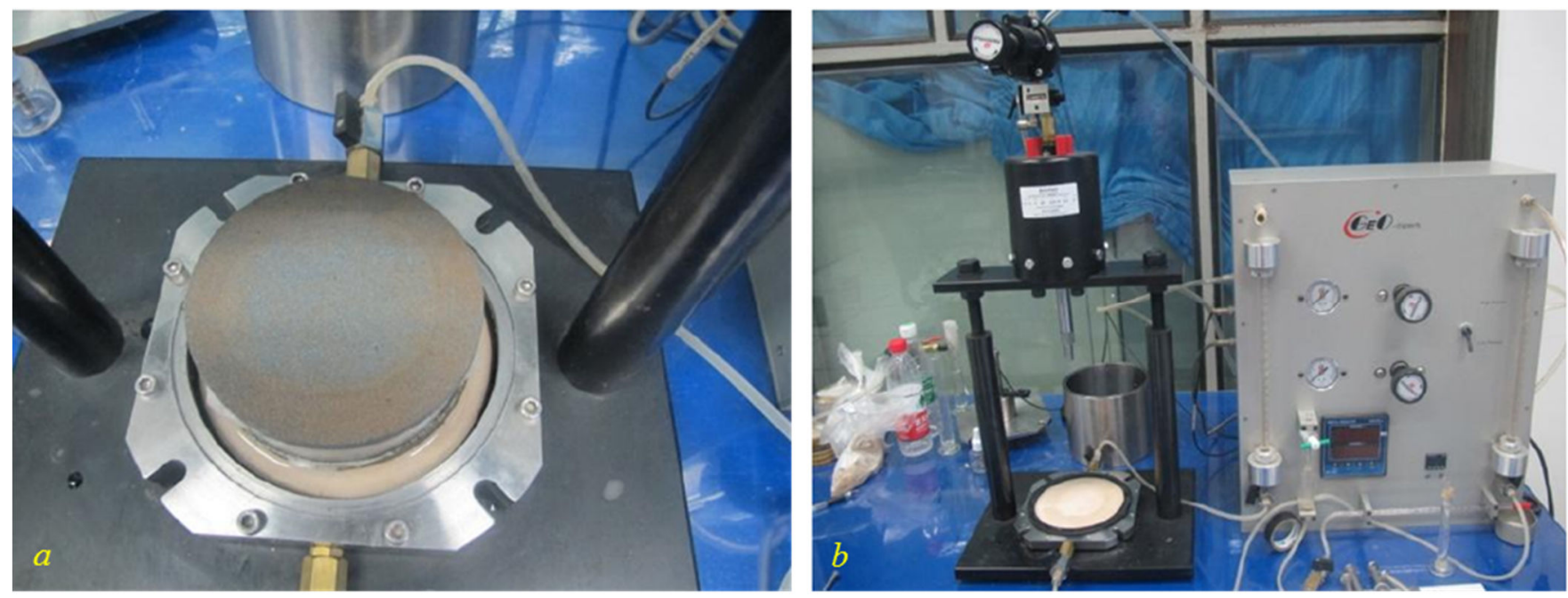

Fig. 2 The details of SWCC test. a) sample installation; b) volumetric pressure plate extractor

The volume-pressure plate extractor is illustrated in Figure $2 \mathrm{~b}$. The maximum matric suction value that the extractor can measure is 1 bar. Based on this, the pore air pressure was set at zero and maintained it as a constant. The matric suction was set to different levels as $0 \mathrm{kPa}, 2 \mathrm{kPa}, 4$ $\mathrm{kPa}, 8 \mathrm{kPa}, 16 \mathrm{kPa}, 32 \mathrm{kPa}$ and $64 \mathrm{kPa}$, respectively. At each level, if there is no further water output from the sample and then the matric suction was escalated to the next level. The matric suction level was increased to the peak value and then constantly decreased to 0 . When the suction value remained stable, we recorded the output water volume. The results are listed in Table 3.

Table 3 Pressure plate test results.

\begin{tabular}{|c|c|c|c|c|}
\hline & $\mathrm{MS}(\mathrm{kPa})$ & $\mathrm{DV}(\mathrm{ml})$ & $\mathrm{MC}(\%)$ & $S r(\%)$ \\
\hline \multirow{7}{*}{ D } & 0 & 0 & 27.66 & 100 \\
\hline & 2 & 44.5 & 24.91 & 89.93 \\
\hline & 4 & 10.05 & 11.54 & 41.95 \\
\hline & 8 & 8 & 5.89 & 20.45 \\
\hline & 16 & 4 & 3.84 & 12.67 \\
\hline & 32 & 2.3 & 2.11 & 6.13 \\
\hline & 64 & 1.5 & 0.03 & 0.09 \\
\hline \multirow{6}{*}{ A } & 64 & 0 & 0.012 & 0.47 \\
\hline & 32 & -1.71 & 0.47 & 1.61 \\
\hline & 16 & -2.34 & 1.04 & 3.17 \\
\hline & 8 & -14.5 & 3.91 & 12.83 \\
\hline & 4 & -33 & 9.75 & 34.83 \\
\hline & 0 & -46 & 17.29 & 65.5 \\
\hline
\end{tabular}

$* \overline{\mathrm{D}-\text { dehumidifying process, } \mathrm{A}-\text { absorption process; } \mathrm{MS}}$ matric suction, DV - drainage volume; MC - moisture content; $\mathrm{Sr}$ - saturation rate

\subsection{Mechanical Strength Analysis}

A laboratory test of shear strength was conducted to analyze the shear strength of the morainic material under different saturation rates. Table 2 shows that more than half of the samples collected from the moraine accumulation in Xiaoqi Village have particle sizes larger than $2.0 \mathrm{~mm}$. Hence, the portable multi-functional tester of rock and soil mechanical properties is selected to conduct larger-scale shear strength laboratory test.

Since the saturation rate cannot be directly controlled, we can only control the moisture content of the test sample. In order to obtain the value of the mechanical strength at a specific saturation rate, the formula to transform saturation rate into moisture content developed by Pellet et al (2013) is used:

$$
S r=\frac{w d_{s}}{e} \%
$$

where $w$ is the volumetric moisture content; $d_{s}$ is the specific gravity of particles; $e$ is the void ratio.

Based on Formula (1), the samples were prepared and allocated in 10 classes with the different saturation rate through controlling the moisture content (Spagnoli et al 2012) and each class contains five samples (Fig. 3b).

In laboratory experiments, the multistage shear test is normally conducted to determine rock and soil mechanical properties (Khalili et al 2004, Soonkie et al 2011). The shear strength values were derived from the test results obtained by Rock and Soil Mechanical Multi-functional Tester (SMT) (Fig. 3). Five different normal stresses, $0.2 \mathrm{MPa}, 0.4 \mathrm{MPa}$, $0.6 \mathrm{MPa}, 0.8 \mathrm{MPa}$ and $1.0 \mathrm{MPa}$, were gradually exerted on the samples with the same saturation rate. The vertical stress in each single experiment remained constant. Then the value of the pressure gage in shear cylinder was recorded when the 
sample was destroyed. In each saturation rate class, shear strengths at different normal stresses were measured (see Code for geotechnical testing: S1237-1999). The cohesion and friction angle of the soil samples for each class were calculated from the curve of shear strength versus normal stress (Soonkie et al 2011). Finally, the shear strengths of the soil samples in different classes were calculated by using the Mohr-Coulomb criterion.
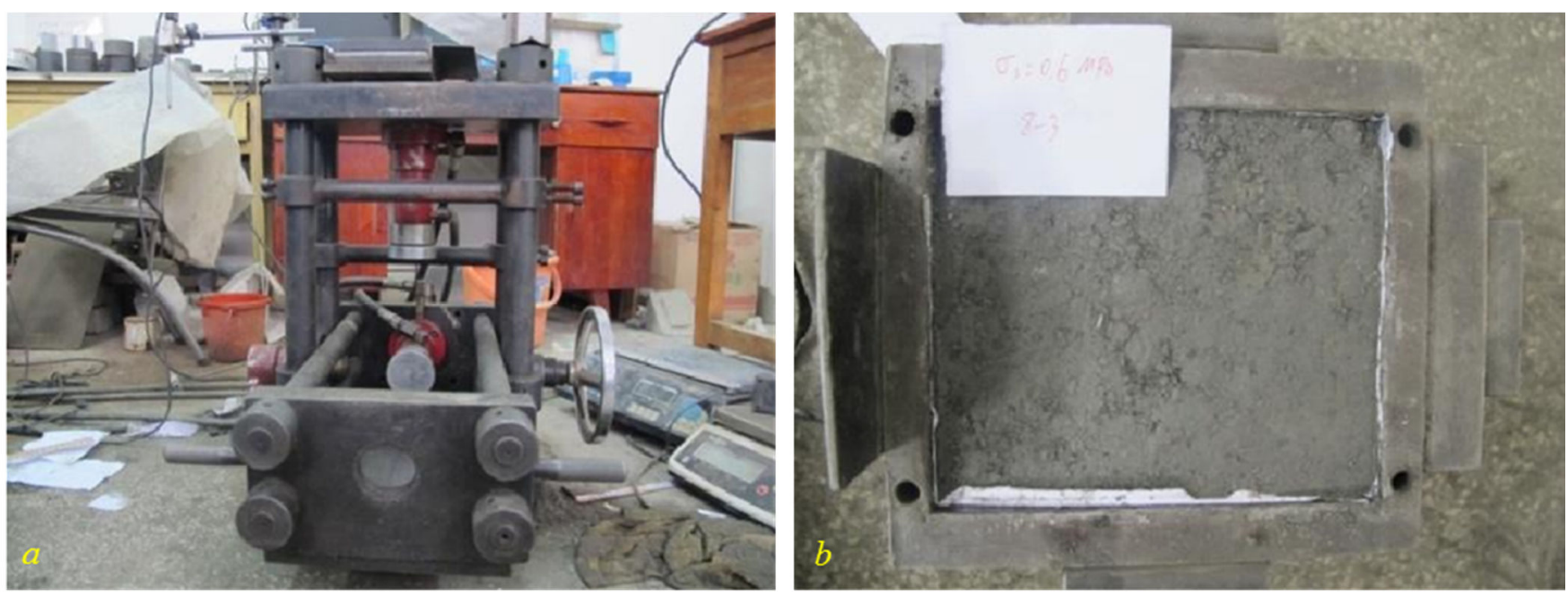

Fig. 3 The rock and soil multi-functional tester for (a) testing rock and soil mechanical properties, and (b) breccia test sample

The results are illustrated in Fig. 4 and show that the soil has a high mechanical strength under the condition of natural moisture content. With an increase of its moisture content, the strength value of the samples drops sharply and reaches its minimum when the soil sample approaches $100 \%$ saturation. This indicates that the collected samples have special high strength and low compressibility under lowhumidity. The deformation process will accelerate when the material reaches its full saturation (Sheng and Yang 2012). There is a high sensitivity when the friction angle reduces to $1 / 3$ and the cohesion reduces to $1 / 8$ of the original value.

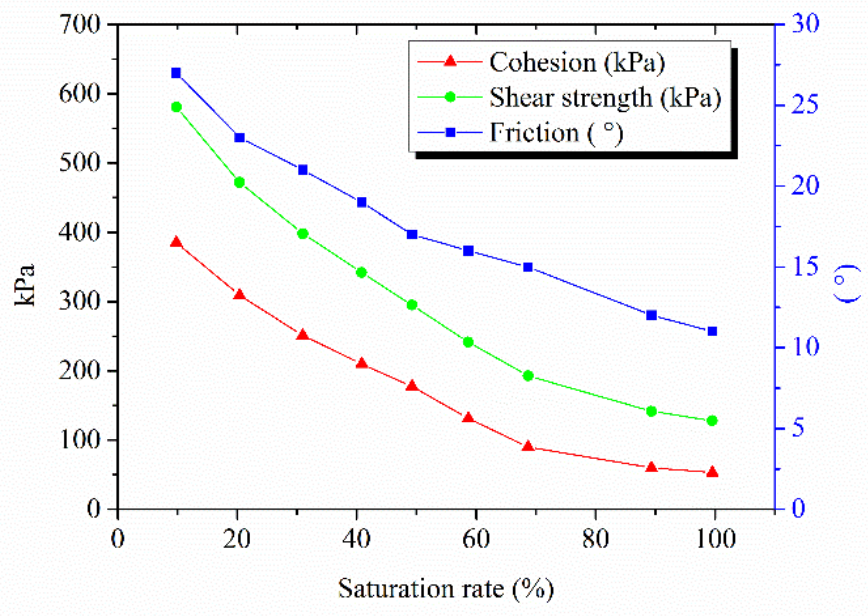

Fig. 4 Mechanical parameters as a function of the saturation rate

\section{Analyses of the Experimental Results}

Based on the experimental results from both SWCC test (Table 3) and mechanical strength test (Fig. 4), we can plot the SWCC curve that shows the negative correlation between the saturation rate and the matric suction. As the initial soil density is constant, the saturation increases with an increase in the moisture content. The SWCC of wetting path is very similar to the SWCC curve of the drying path (Fig. 5)

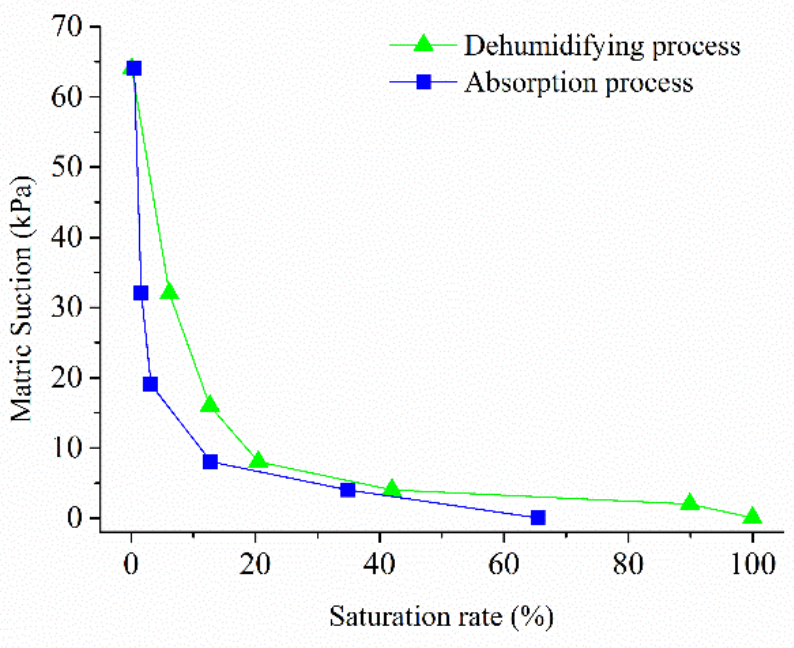

Fig. 5 Numerical relationship between the matric suction and the saturation rate

There is a sharp drop in the matrix suction for the saturation rates between $0 \%$ and $20 \%$. Then it decreases slowly in the interval between $20 \%$ and $100 \%$. The mathematical nonlinear relationship between the two variables in the SWCC curve proposed in the literature is also observed in this research.

The SWCC also reflects the relationship between soil moisture content and the value of matric suction. The values 
of moisture content can be computed by soil saturation rates according to the results in Table 3. Currently most equations used for fitting SWCC are based on experiences. They have many multifarious parameters and are difficult to apply. Hence in this paper, we use the test parameters (Table 3) for fitting.

$$
w=\alpha+\beta \ln \left[\left(\mu_{a}-\mu_{w}\right)+\gamma\right]
$$

where, $w$ is moisture content, $\left(\mu_{a}-\mu_{w}\right)$ is matrix suction; $\alpha$, $\beta$, and $\gamma$ are the fitted parameters.

The fitted values of parameters in equation (2) are listed in Table 4. As shown in Fig. 6, the correlation coefficient R2 for the curve of the drying path equals 0.83 . The correlation coefficient R2 for the curve of the wetting path even reaches 0.92 . The fitting results effectively reveal the characteristics of the SWCC of this particular type of morainic material.

Table 4 Parameters in the fitting equation of SWCC

\begin{tabular}{cccc}
\hline Parameters & $\alpha$ & $\beta$ & $\gamma$ \\
\hline $\mathrm{D}$ & 23.642 & -6.311 & 0.519 \\
\hline $\mathrm{A}$ & 13.546 & -3.365 & 0.341 \\
\hline
\end{tabular}

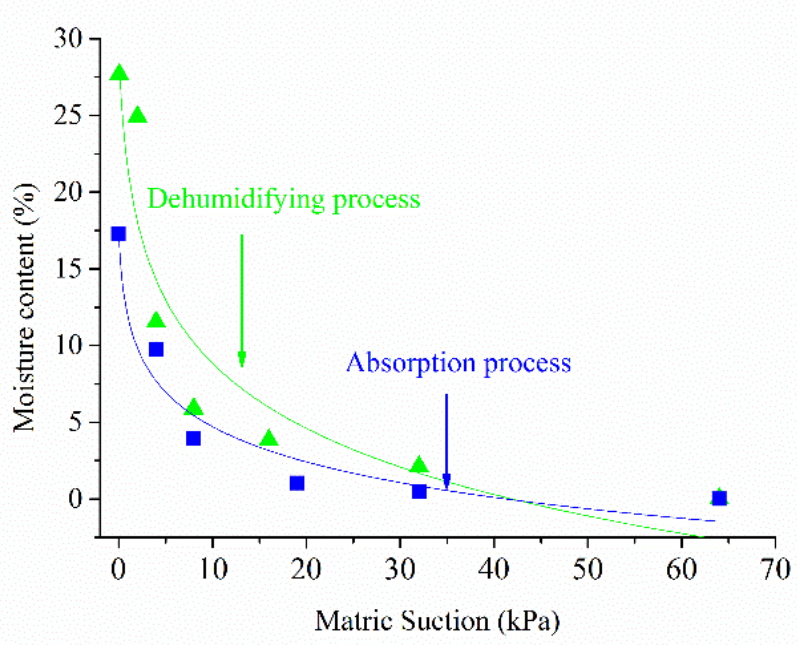

Fig. 6 Fitted results of SWCC

Based on the fitted equation, the volumetric moisture content can be calculated for different values of the matric suction. For a given moisture content, the cohesion, friction angle and shear strength can be calculated with experimental data given in Fig. 5. Details are shown in Table 5.

Table 5 The summary of mechanical strength parameters for brecciated soil

\begin{tabular}{cccccccc}
\hline $\begin{array}{c}\text { Strength } \\
\text { parameters }\end{array}$ & $S r$ & $\begin{array}{c}\text { Cohesion } \\
(\mathrm{kPa})\end{array}$ & $\begin{array}{c}\text { Friction } \\
\text { angle } \\
\left({ }^{\circ}\right)\end{array}$ & $\begin{array}{c}\text { Matric } \\
\text { suction }^{1} \\
(\mathrm{kPa})\end{array}$ & $\begin{array}{c}\text { Matric } \\
\text { suction }^{2} \\
(\mathrm{kPa})\end{array}$ & $\begin{array}{c}\text { Shear } \\
\text { Strength } \\
(\mathrm{kPa})\end{array}$ & $\begin{array}{c}\text { Effective } \\
\text { Stress } \\
(\mathrm{kPa})\end{array}$ \\
\hline Sample 1 & 9.83 & 385.07 & 27.00 & 20.70 & 11.14 & 580.65 & 383.85 \\
\hline Sample 2 & 20.40 & 309.08 & 23.00 & 8.74 & 4.93 & 472.01 & 537.08 \\
\hline Sample 3 & 30.98 & 250.73 & 21.00 & 5.09 & 3.22 & 398.07 & 664.96 \\
\hline Sample 4 & 40.86 & 209.82 & 19.00 & 3.54 & 2.44 & 341.99 & 759.20 \\
\hline Sample 5 & 49.27 & 177.53 & 17.00 & 2.76 & 2.02 & 294.88 & 818.72 \\
\hline Sample 6 & 58.69 & 131.16 & 16.00 & 2.18 & 1.69 & 241.23 & 861.04 \\
\hline Sample 7 & 68.68 & 89.80 & 15.00 & 1.76 & 1.45 & 192.65 & 875.88 \\
\hline Sample 8 & 89.35 & 59.98 & 12.00 & 1.22 & 1.11 & 141.57 & 799.17 \\
\hline Sample 9 & 99.54 & 53.22 & 11.00 & 1.04 & 1.00 & 127.83 & 703.45 \\
\hline
\end{tabular}

*Matric suction ${ }^{1}$ is matrix suction of dehumidifying process; Matric suction ${ }^{2}$ is matrix suction of absorption process.

The difference between experimental results and derived results from traditional methods (Table 1) is significant. Bishop's and Frelund's shear strengths slightly increases with an increase in the saturation rate. Theoretically, both shear strengths reach their maximum values when saturation rate becomes $35 \%$. After that, the correlations turn into negative values. However, for this type of breccia, experimental results show a negative correlation between the shear strength and the saturation rate. The value is only $1 / 3$ of the original one at saturation rate $10 \%$. Hence, the traditional methods do not work well for this type of breccia. A revised formula to explain the experimental results are needed.

\section{A Revised Strength Formula Based on Mohr- Coulomb Criterion}

In the above discussions, this type of breccia shows significant water sensitivity. As shown in Fig. 7, using traditional mechanical models to determine the unsaturated mechanical properties is invalid. Due to its mineral composition, occurrence conditions and the high relevancy 
between its migration processes and the origin of migration snow, it has high water sensitivity. By Bishop's method, the range of effective stress is between -207.32 and 248.69 for this type of breccia. The width of this range refers dynamic experimental results with enormous uncertainty and this method failed to explain the mechanical characteristics of this type of breccia. Hence, a revision of the shear strength formula based on Mohr-Coulomb criterion is necessary.

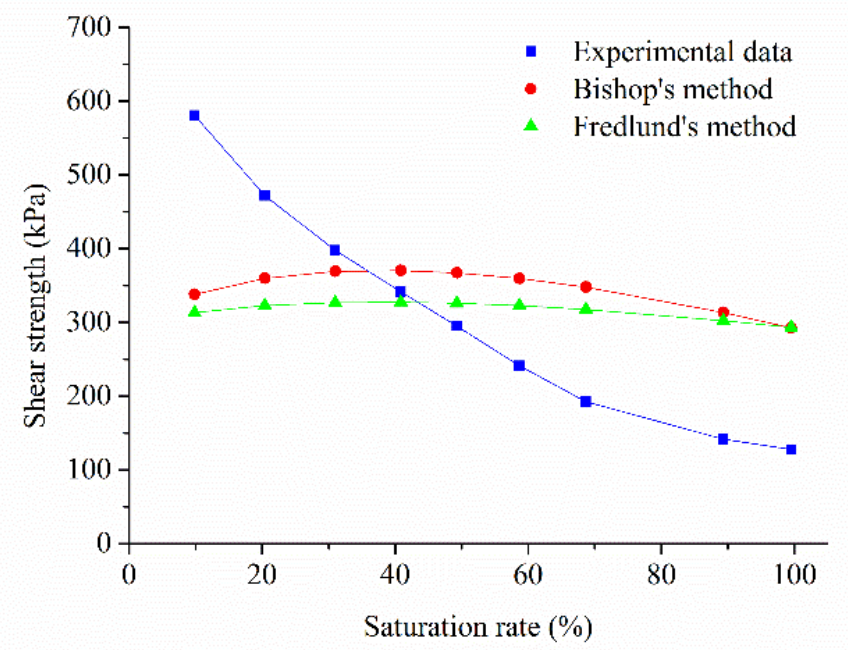

Fig.7 Comparison between the classical methods and the laboratory experiment results

As indicated by previous research (Bishop 1959, Bishop and Blight 1963, Fredlund and Rhadajo 1993, Sillers el al 2001), unsaturated soil shear strength formula is largely impacted by matric suction as an independent variable. Therefore, in this paper, we propose a mathematical formula according to the mechanical characteristics of this brecciated soil:

$$
\tau_{f}=c^{\prime}+\sigma \tan \varphi^{\prime}+R
$$

The formula above is constructed based on MohrCoulomb criterion. The $R$ denotes the cohesion intercept.

\subsection{Evaluation of Cohesive Intercept}

In order to express the cohesion for our revised model, this paper selected saturation rate and matric suction as predictive variables of the cohesion offset $\mathrm{R}$ (intercept).

$$
R=f\left(S r, \mu_{a}-\mu_{w}\right)
$$

Also we define $B_{0}$ as shear strength, $B_{i}$ as the product of the power of saturation and the power of matric suction, which can be expressed as:

$$
B_{i}=S r^{e *}\left(\mu_{a}-\mu_{w}\right)^{f}
$$

Then the correlation coefficient of $B_{0}$ and $B_{i}$ under the condition that $e, f$ are variables is:

$$
\mathrm{y}_{\mathrm{i}}(\mathrm{k})=\frac{(\mathrm{y}+\mathrm{z} \rho)}{\left(\frac{1}{\mathrm{n}} \sum_{1}^{\mathrm{n}} \Delta_{\mathrm{i}}(\mathrm{k})+\beta \rho\right)}
$$

where, $\Delta_{\mathrm{i}}(\mathrm{k})=\left|x_{k i}-x_{\text {oi }}\right|,(i=1,2, \ldots, \mathrm{m} ; k=1,2, \ldots$, $\mathrm{n}), \quad \mathrm{y}=\min \Delta_{\mathrm{i}}(\mathrm{k}), \quad \mathrm{z}=\max \Delta_{\mathrm{i}}(\mathrm{k}), \quad \mathrm{x}$ denotes the parameter between $B_{0}$ and $B_{i}, \rho$ is discrimination coefficient. In most cases $\rho=0.5$.

The overall correlation coefficient of $B_{0}$ and $B_{i}$ is expressed in Eqn. (7):

$$
\begin{aligned}
& \mathrm{r}_{\mathrm{i}}=\frac{1}{\mathrm{~m}^{* \mathrm{n}}} \sum_{1}^{\mathrm{m}^{*} \mathrm{n}} \mathrm{y}_{\mathrm{i}}(\mathrm{k}),(i=1,2, \ldots \ldots, m ; k= \\
& 1,2, \ldots \ldots, n)
\end{aligned}
$$

After inputting the experimental data in Table 5 into the proposed model, we have found that when $e=1$ and $f=1$, the overall correlation coefficient reaches its maximum. Therefore, we can define the cohesion offset using Eqn. (8):

$$
\mathrm{R}=\mathrm{p} \times\left(\mu_{\mathrm{a}}-\mu_{\mathrm{w}}\right) \times \mathrm{Sr}-\mathrm{q}
$$

where $p$ is the correlation coefficient, $q$ is the field coefficient.

\subsection{Parameter Estimation}

Using data in Table 5, the mechanical strength parameters were estimated through maximum likelihood maximization. By MATLAB, we get $p=5.671$ and $q=630.1$. It can be seen from Fig. 8 that the proposed formula has better performance in fitting. Therefore, we can derive the following strength formula:

$$
\begin{aligned}
& \quad \tau_{f}=c^{\prime}+\sigma \tan \varphi^{\prime}+p \times\left(\mu_{a}-\mu_{w}\right) \times S r-q \\
& =\bar{c}+\sigma \tan \varphi^{\prime}
\end{aligned}
$$

where c' is the effective cohesion of saturated soil; $\varphi$ ' is the effective internal friction angle of saturated soil; $\overline{\mathbf{c}}$ is the fixed cohesion, and $\overline{\mathrm{c}}=\mathrm{c}^{\prime}+\mathrm{R}$.

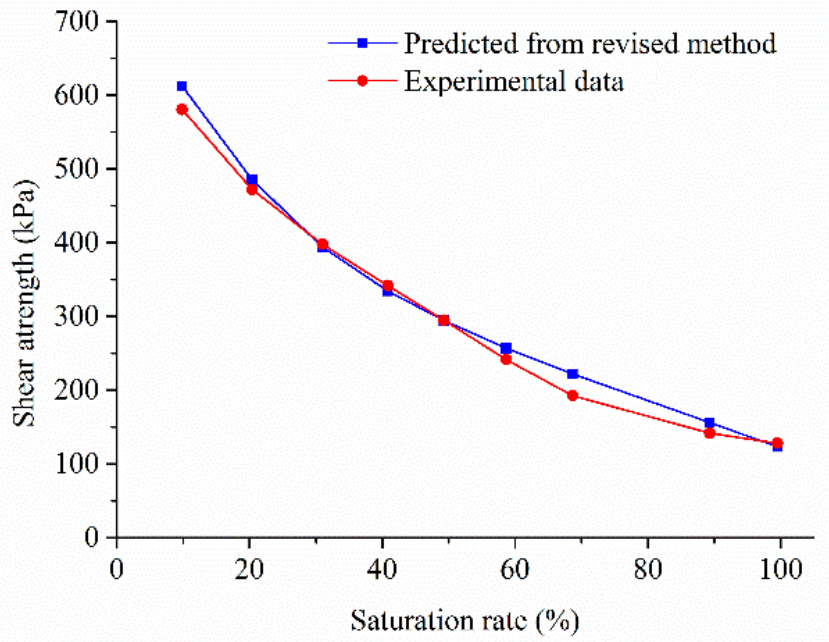

Fig. 8 Performance evaluation of prediction based on the revised method

In Fig. 8 the predicted values derived from our proposed revised formula have less error in comparison with traditional ones. It has better performance in interpreting the 
numerical relationship between the shear strength and the moisture content of this specific type of breccia. Here we use the mean absolute percentage error (MAPE) and standard deviation of MAPE to evaluate the overall performance of all methods. The formula to compute MAPE is expressed in Eqn. (10).

$$
M A P E=\frac{1}{n} \sum_{i=1}^{n}\left|\frac{y_{i}-\hat{y}_{i}}{y_{i}}\right|
$$

The performance of each method is listed in Table 6 . The revised formula has less error in comparison with traditional methods.

Table 6 MAPE and Standard deviation of MAPE

\begin{tabular}{cccc}
\hline Methods & $\begin{array}{c}\text { Revised } \\
\text { formula }\end{array}$ & $\begin{array}{c}\text { Bishop's } \\
\text { formula }\end{array}$ & $\begin{array}{c}\text { Fredlund } \\
\text { formula }\end{array}$ \\
\hline MAPE & $10 \%$ & $36 \%$ & $38 \%$ \\
\hline $\begin{array}{c}\text { Std of } \\
\text { MAPE }\end{array}$ & $8 \%$ & $22 \%$ & $26 \%$ \\
\hline
\end{tabular}

\section{Conclusions}

In this paper, soil-water characteristic curves and pressure plate test results are employed to analyze the strength characteristics of breccia sampled from Xiaoqi Village. There is a significant negative correlation between the saturation rate and the mechanical strength. This indicates extremely high water-sensitivity of this type of unsaturated soil.

The traditional Bishop's and Fredlund's formulas to compute the unsaturated strength are not adequate to predict the shear strength of breccia type soils at various suction levels. Hence in this paper, a revised formula based on MohrCoulomb criterion is established to model the mechanical characteristics of moraines. A cohesive offset containing the saturation rate and suction for unsaturated conditions is introduced. Numerical results confirmed the effectiveness of the proposed formula for deriving the shear strength of this specific breccia. In future research, similar approach can be applied for any types of breccia investigation.

\section{Acknowledgements}

This work was supported by the National Natural Science Foundation of China (Grant No. 41572291) and the National Basic Research Program (973 Program, Grant No. 2014CB744703; 2013CB733200). We would like to appreciate Prof. T.W.J. van Asch (Utrecht University, Netherlands) for his helpful suggestions to improve our manuscript.

\section{References}

Barden, L., A. McGown and K. Collins, 1973. The collapse mechanism in partly saturated soil. Engineering Geology, 7(1): 49 - 60.
Bishop, A.W., 1959. The principle of effective stress. Teknisk Ukeblad, 106(39): 859 - 863.

Blight, G.E., 1967. Effective stress evaluation for unsaturated soils. Journal of the Soil Mechanics and Foundations Division, 93(2): 125 - 148.

Bishop, A.W. and G.E. Blight, 1963. Some aspects of effective stress in saturated and partly saturated soils. Geotechnique, 13(3): 177 - 196.

Brooks, R.H. and A.T. Corey, 1964. Hydraulic properties of porous media and their relation to drainage design. Trans. ASAE, 7(1): 26 - 28.

Campbell, G.S., 1974. A simple method for determining unsaturated hydraulic conductivity from moisture retention data. Soil Science, 117: $311-314$.

Çokça, E. and H.P. Tilgen, 2010. Shear strength-suction relationship of compacted Ankara clay. Applied Clay Science, 49(4): 400 - 404.

Coleman, J.D., 1962. Stress strain relations for partly saturated soils. Geotechnique, 12(4): 348 - 350.

Croney, D., J.D. Coleman and W.P.M. Black, 1958, Movement and distribution of water in relation to highway design and performance, Highway Research Board Special Report, No. 40. Washington Highway Research Record.

Fredlund, D.G. and N.R. Morgenstern, 1977. Stress state variables for unsaturated soils. Journal of the Geotechnical Engineering Division, ASCE, 103(GT5): 447 - 466.

Fredlund, D.G. and H. Rhadajo, 1993. Soil Mechanics for Unsaturated Soils. John Wiley and Sons, New York

Gens, A. and E.A. Alonso, 1992. Frame wok for the behavior of unsaturated expansive clays. Canadian Geotechnical Journal, 29: 1013 - 1032.

Gong, X.N., 2000. Prospects for the development of geotechnical engineering in the 21th century. Chinese Journal of Geotechnical Engineering, 22(2): 238 - 242.

Jennings, J.E.B. and J.B. Burland, 1962. Limitations to the use of effective stresses in partly saturated soils. Geotechnique, 12(2): 125 - 144.

Khalili, N., F. Geiser and G.E. Blight, 2004. Effective stress in unsaturated soils: review with new evidence. International Journal of Geomechanics, 4(2): 115 - 126.

Pellet, F. L., M. Keshavarz and M. Boulon, 2013. Influence of humidity conditions on shear strength of clay rock discontinuities. Engineering Geology, 157(8): 33 - 38.

Sheng, D. 2011. Review of fundamental principles in modelling unsaturated soil behaviour. Computers \& Geotechnics, 38(6): 757 - 776.

Sheng, D.C., S.W. Sloan and A. Gens, 2004. A constitutive model for unsaturated soils: thermo-mechanical and algorithmic aspects. Computational Mechanics, 33: 453 -465 .

Sheng, D.C. and C. Yang, 2012. Discussion of fundamental principles in unsaturated soil mechanics. Chinese Journal of Geotechnical Engineering, 34(3): 438 - 456.

Sillers, W.S., D.G. Fredlund and N. Zakerzadeh, 2001. Mathematical attributes of some soil - water characteristic curve models. In: Unsaturated Soil Concepts and Their Application in Geotechnical Practice 
(pp. 243 - 283). Springer Netherlands.

Soonkie, N., M. Gutierrez, P. Diplas and J. Petrie, 2011. Determination of the shear strength of unsaturated soils using the multistage direct shear test. Engineering Geology, 122(3): 272 - 280.

Spagnoli, G., H. Stanjek and A. Sridharan. 2012. Influence of ethanol/water mixture on the undrained shear strength of pure clays. Bulletin of Engineering Geology and the Environment, 71(2): 289 - 398.

van Genuchten, M.TH. and F.J. Leiji, 1992. Indirect Methods for Estimating the Hydraulic Properties of Unsaturated Soils. University of California Press: 1 - 14. California

Wheeler, S.J., R.S. Sharma and M.S.R. Buisson, 2003. Coupling of hydraulic hysteresis and stress-strain behavior in unsaturated soils. Geotechnique, 53(1): 41 54.

Whitman, R.V., 1984. Evaluating calculated risk in geotechnical engineering. Journal of Geotechnical Engineering, 110(2): 143 - 188.

$\mathrm{Xu}$, Y.F., 2000. Research on bearing capacity of expansive ground. Rock Mechanics and Engineering, 22(2): 238 242.

Xu, Y.F., 2005. Explanation of scaling phenomenon based on fractal fragmentation. Mechanics Research Communications, 32(2): 209 - 220.

Yang, Q., C.Q. Zhang and M.T. Nie 2004. Generalized effective stress principle of unsaturated soil based on microstructure quantitative analysis. Dalian University of Technology, 44(4): 556 - 559.

Zeng, L.J., 2014. Intensity and Stability Study of the Xiaoqi Village Glacial Till Slope Based on SWCC. Chengdu University of Technology Press.

Zheng, H.C., S.W. Yong and Y.X. Ding, 1994. Effective stress in unsaturated soils. Geotechnical Engineer, 16(3): $64-71$. 